\title{
В.В. Маленков
}

\section{ТЕМПОРАЛЬНЫЙ ОБРАЗ РОССИИ В ДИНАМИКЕ ПРЕДСТАВЛЕНИЙ ЖИТЕЛЕЙ ТЮМЕНИ ${ }^{1}$}

\begin{abstract}
Темпоральный образ страны рассматривается в статье как важнейшая составляющцая структуры нации, нациеформирующий элемент современного рефлексируюшего общества. Сделан акиент на выявлении массовых представлений жителей Тюмени о прошлом, настоящем и будущем России. Эмпирической основой являются данные анкетного опроса 2015 и 2017 гг., что позволило сделать выводы относительно изменения настроений за два прошедших года.

Ключевые слова: нация, историческая память, темпоральный образ страньл.
\end{abstract}

Значительную часть национально-гражданской идентичности составляет темпоральный образ страны, в которой проживает человек. Данный образ представляет осознание прошлого, настоящего и будущего страны и отождествление с ним. В зависимости от степени идентификации с историческими конструктами некоторой превалирующей части граждан на макроуровне общества формируется темпоральная структура нации. В этом смысле можно говорить о нациях прошлого, настоящего и будущего. По всей видимости, формирование российской нации проходит сегодня в русле приоритета прошлого над будущим, т.е. будущее транслируется в виде модели хорошего прошлого [1. С. 150]. Безусловно, социальная и культурная память является важным элементом любого современного общества. Как отмечал Ю.М. Лотман, «иногда «прошедшее» культуры для ее будущего состояния имеет большее значение, чем ее «настоящее» [2. С. 615]. Однако зацикливание на прошлом и отсутствие должного внимания к будущему в форме целеполагания, моделей развития, масштабной рефлексии о будущем приводит к упадку, архаизации.

Следует отметить, что в конкурентных обществах горизонтального типа на формирование темпоральной стратегии нации оказывают влияние множество субъектов, представляющих государство и гражданское общество. В российском же публичном пространстве вертикального типа ключевую роль в формировании темпоральной структуры макросообщества играет идеологический аппарат государства, в результате чего у нас, по мнению В.А. Ачкасова, наблюдается «ограниченность репертуара «политически пригодного» прошлого и использование его исключительно для легитимации текущих решений и действий власти» [3. С. 189]. В рамках официально признанной версии прошлого современность интерпретируется в терминах восстановления утраченного величия страны, политическое использование [4] великодержавного нарратива направлено на обоснование настоящего и создание ощущения его возврата в реальность российского нациестроительства.

\footnotetext{
${ }^{1}$ Статья выполнена при поддержке гранта РНФ № 17-78-20062 «Жизненные стратегии молодежи нового рабочего класса современной России».
} 
В результате массовое сознание россиян наполнено стереотипизированными представлениями о прошлом нашей страны. Разные исторические эпохи имеют свои особые мифологизированные образы, актуализируемые в зависимости от существующих «политических трендов». Изучению массовых представлений о прошлом России посвятили свои работы О.В. Головашина [5], Л.Д. Гудков [6], Б.В. Дубин [7], Т.В. Евгеньева и А.В. Селезнева [8], В.А. Касамара и А.А. Сорокина [9] и др.

\section{Методика исследования}

Эмпирической базой данной статьи послужили данные, полученные в результате проведения мониторингового исследования. Первый замер осуществлен в марте - апреле 2015 г., второй - в марте - апреле 2017 г. Методом сбора данных являлся анкетный опрос. Объектом исследования выступили жители Тюмени в возрасте от 17 до 77 лет. Объем репрезентативной по признакам пола и возраста выборки в обоих замерах составил 1600 респондентов.

В процессе анализа данных были выделены четыре возрастные группы на основании поколенного подхода. В первую группу (советское поколение) включены респонденты, родившиеся до 1972 г. Вторая группа (позднесоветское поколение) состояла из родившихся в 1973-1984 гг. В третью группу (постсоветская переходная генерация) вошли родившиеся с 1985 по 1993 г. Четвертая группа (постсоветское поколение) охватила молодежь 1994-2000 гг. рождения [10. C. 66]. Выделение поколенческих групп основано на опыте непосредственного взаимодействия с базовыми советскими и постсоветскими институтами, определившими политическую и гражданскую социализацию [11, 12].

\section{Темпоральная идентичность: Россия прошлая, современная или будущая}

Темпоральная идентичность представляется здесь как отождествление страны с тем или иным ее временным (темпоральным) образом. По этому основанию можно выделить три модели идентичности: ретроспективная идентичность (апелляция к «идеальному прошлому» страны), идентичность «здесь-и-сейчас» (апелляция к настоящему, отказ определять страну через прошлое и будущее), перспективная идентичность (апелляция к «идеальному будущему» страны). Первая модель предполагает идеализацию некоей исторической эпохи, «воображаемого» в массовом сознании периода в истории, который определяет Россию в качестве исторического субъекта.

При этом необходимо учитывать, что массовая историческая память, в отличие от системного взгляда профессионального историка, представляет некую мозаику разбросанных образов, не всегда четко зафиксированных во времени. Отсюда абстрактная апелляция к истории в форме «вот раньше...», «когда-то...» и т.д.

Для изучения массовых представлений о темпоральной идентичности России был сформулирован ряд вопросов, первый из которых направлен на фиксацию представлений о России в контексте прошлого, будущего и настоящего, где прошлое было представлено тремя «воображаемыми историческими концептами»: «Святая Русь», «Российская империя», «Советский Союз». Необходимо отметить, что, во-первых, ограниченный ряд исторических концептов обусловлен тем, что превалирующая часть респондентов именно 
их указывает в качестве «идеализированных эпох» в истории России. Вовторых, данные концепты используются в исследовании как категории исторической политики и как воображаемые исторические модели в общественном сознании, исторической памяти общества, но не как обозначение периодов, которыми оперирует историческая наука.

Так, концепт «Святая Русь» вообще не является научно-историческим, а скорее «связан с дискурсами протонационального или национального самосознания» [13. С. 319]. Надо признать, что он весьма размыт, имеет множество коннотаций. Но в массовом сознании образ Святой Руси отсылает к периоду от Крещения Руси до петровских преобразований. Концепты «Российская империя» и «Советский Союз» также в исследовании выступают как доминантные идеальные модели-образы исторического сознания российского общества. Поскольку исследование является социологическим, описывающим категории общественного сознания, а не историческим, именно в этом контексте мы и используем данные понятия.

Использование для обозначения будущего России таких признаков, как «Великая», «возрожденная», объясняется необходимостью его идеализации в контексте формулируемого вопроса.

По результатам замера 2017 г. большинство респондентов ассоциировали себя с современной Россией. Вероятно, здесь работает тот же механизм идеализации, что и в отношении прошлого и будущего. Данную модель идентификации можно обозначить как отказ от необходимости возврата к идеальному прошлому, а не идеализацию настоящего страны. Характерно, что по сравнению с 2015 г. данный тип идентификации (здесь-и-сейчас) даже несколько усилился - с 38,5\% в 2015 г. до 44,5\% в 2017 г.

Ретроспективная идентичность, напротив, существенно теряет свои прежние позиции. С прошлым страны ассоциировали себя 26,5\% опрошенных (в 2015 г. - 37,1\%). В частности, со Святой Русью - 6,8\% (в 2015 г. $10,9 \%$ ), с Российской империей $-8,1 \%$ респондентов (в 2015 г. - 12,0\%), с Советским Союзом - 12,6\% (в 2015 г. - 14,2\%).

С будущей возрожденной Великой Россией себя идентифицировали лишь 15,3\%. Однако по сравнению с 2015 г. (11,4\%) наметился рост данного показателя на $3,9 \%$.

Следует отметить также, что количество безразличных, не ассоциирующих себя ни с каким из предложенных темпоральных образов России, уменьшилось на 5,1\% - с 12,3\% в 2015 г. до 7,2\% в 2017 г.

Таким образом, можно констатировать: а) значение будущего несколько усилилось в 2017 г. по сравнению с 2015 г. «Великое» будущее России для респондентов более реалистично, нежели двумя годами ранее. С пятого места в ранговой таблице данная позиция переместилась на второе; б) значение Советского Союза в структуре темпоральной идентичности уменьшилось незначительно, однако данная позиция со второго места переместилась на третье в иерархии ассоциаций; в) изменилось значение отдаленного прошлого, хотя на изменение места в ранговой таблице это практически не повлияло. Российская империя как часть образа России осталась на четвертом месте, а Святая Русь переместилась с шестого места на пятое.

Вместе с тем позиции разных поколенческих групп практически по всем рассматриваемым переменным весьма существенно различаются. Результаты 
исследования в разрезе поколений представлены в табл. 1. В частности, степень ассоциации со Святой Русью заметно уменьшилась у трех младших поколений, но несколько увеличилась в поколении советском. Российская империя усилила позиции в структуре темпоральной идентичности самого младшего и самого старшего поколения, однако ослабила позицию в срединных поколениях. Степень ассоциации с Советским Союзом довольно существенно уменьшилась во всех группах, кроме самой старшей, в которой, наоборот, немного усилилась (с 25,7\% в 2015 г. до 28,8\% в 2017 г.).

Таблица 1. С каким образом России ассоциируют себя респонденты, \%

\begin{tabular}{|c|c|c|c|c|c|c|c|c|}
\hline \multirow[t]{2}{*}{ Вариант ответа } & \multicolumn{2}{|c|}{$\begin{array}{c}\text { Постсоветское } \\
\text { поколение }\end{array}$} & \multicolumn{2}{|c|}{$\begin{array}{c}\text { Постсоветская пере- } \\
\text { ходная генерация }\end{array}$} & \multicolumn{2}{|c|}{$\begin{array}{c}\text { Позднесоветское } \\
\text { поколение }\end{array}$} & \multicolumn{2}{|c|}{$\begin{array}{l}\text { Советское } \\
\text { поколение }\end{array}$} \\
\hline & 2015 & 2017 & 2015 & 2017 & 2015 & 2017 & 2015 & 2017 \\
\hline Святая Русь & 13,1 & 8,3 & 11,2 & 6,1 & 9,5 & 2,0 & 8,8 & 10,2 \\
\hline Российская империя & 16,3 & 6,9 & 11,2 & 12,2 & 8,3 & 11,8 & 8,8 & 1,7 \\
\hline Советский Союз & 4,1 & 1,4 & 10,3 & 8,2 & 27,2 & 15,7 & 25,7 & 28,8 \\
\hline $\begin{array}{l}\text { Будущая возрожденная } \\
\text { Великая Россия }\end{array}$ & 8,8 & 9,7 & 13,1 & 14,3 & 14,2 & 19,6 & 10,5 & 16,9 \\
\hline Современная Россия & 38,8 & 52,8 & 40,7 & 44,9 & 35,5 & 45,1 & 36,8 & 33,9 \\
\hline Безразлично, ни с каким & 18,1 & 13,9 & 11,2 & 6,1 & 4,7 & 5,9 & 7,6 & 1,7 \\
\hline Затруднились ответить & 1,2 & - & 2,3 & - & 0,8 & - & 0,8 & - \\
\hline Всего & 100,0 & 100,0 & 100,0 & 100,0 & 100,0 & 100,0 & 100,0 & 100,0 \\
\hline
\end{tabular}

Усиление идентичности с современной Россией не коснулось самого старшего поколения. В остальных же группах оно наблюдается, особенно среди представителей постсоветского поколения, где степень идентификации с современной Россией выросла на 14,0\%. Неким абсолютным трендом стало усиление ассоциации с «будущей возрожденной Великой Россией» во всех без исключения поколенческих группах. Вместе с тем более отчетливо данная тенденция проявилась в старших поколениях - позднесоветском и советском, где рост данной ассоциативной связи более существен по сравнению с двумя младшими группами.

\section{Идеальное прошлое России}

Существенным компонентом структуры темпорального образа России являются представления о наиболее успешном периоде в истории страны как важной части картины идеального прошлого. Зафиксированные цифры двух замеров могут свидетельствовать об изменении данной картины.

В отличие от предыдущего вопроса, предполагающего ответ на закрытый перечень предложенных вариантов, данный был открытым. Респонденты вписывали свои варианты ответа в пустые строки. При обработке полученных данных осуществлялась их систематизация. Например, период правления Л.И. Брежнева респонденты могли маркировать как «Брежнев», «брежневский период», «застой», «1964-1982» и т.д. В предложенной далее табл. 2 данный период обозначен как «Период правления Брежнева («застой»). Поскольку упоминания советского периода встречались в ответах наиболее часто, мы выделили в отдельную строку вариант «СССР» (варианты ответа «СССР», «Советский Союз», «советское время», «советы» и т.д.) и другие периоды, упоминаемые отдельно, но принадлежащие советской эпохе («Великая Отечественная война», «хрущевская оттепель» (период правления Н.С. Хрущева) и т.д. 
Таблица 2. Мнение респондентов о самом успешном периоде в истории России

\begin{tabular}{|l|c|c|c|c|}
\hline \multirow{2}{*}{ Вариант ответа } & \multicolumn{2}{c|}{ Ответившие, \% } & \multicolumn{2}{c|}{ Ранг } \\
\cline { 2 - 5 } & 2015 & 2017 & 2015 & 2017 \\
\hline СССР & 23,4 & 20,9 & 1 & 1 \\
\hline Россия 2000-х (современная Россия) & 21,2 & 16,6 & 2 & 3 \\
\hline Победа в Великой Отечественной войне & 11,6 & 9,6 & 3 & 6 \\
\hline Правление Петра І & 10,2 & 18,2 & 4 & 2 \\
\hline Дореволюционный период & 9,4 & 12,8 & 5 & 4 \\
\hline Период правления Брежнева («застой») & 7,8 & 10,2 & 6 & 5 \\
\hline Девяностые годы ХХ в. & 3,8 & 1,1 & 7 & 10 \\
\hline «Хрущевская оттепель» & 3,2 & 2,1 & $8-9$ & $8-9$ \\
\hline «Перестройка» & 3,2 & - & $8-9$ & - \\
\hline От образования СССР до начала ВОВ & 2,4 & 0,5 & 10 & 11 \\
\hline Путинская Россия & 2,2 & 5,9 & 11 & 7 \\
\hline Послевоенный период (1945-1953 гг.) & 1,4 & 2,1 & 12 & $8-9$ \\
\hline
\end{tabular}

Аналогичным образом систематизировались и другие ответы. Варианты ответа, где упоминается имя нынешнего президента Росиии («Путин», «путинская Россия, «правление Путина), обозначены как «Путинская Россия». Данный вариант отделен от «Современной России», в которой объединены ответы, где упоминается период с 2000 г. и вплоть до дня проведения опроса.

В таблицу не вошли ряд периодов. В частности, не упоминается в ответах респондентов период от революции 1917 г. до образования СССР. Нет среди ответов респондентов и периода 1991-1993 гг. Вариант «Девяностые годы ХХ века» включает 1994-1999 гг. Упоминание правителей и периоды до 1917 г. объединены в категорию «Дореволюционная Россия», поскольку упоминания отдельных периодов и правителей не превышают одного процента.

По результатам исследования можно зафиксировать следующие тенденции. Во-первых, произошло существенное уменьшение доли считающих советский период наиболее успешным в истории России. Если в 2015 г. количество указавших на это составляло 53,0\% (более половины респондентов), то в 2017 г. аналогичное мнение высказали уже 45,4\%. При этом непосредственно советский период (СССР, Советский Союз и т.д.) отметили 20,9\% (в 2015 г. $23,4 \%$ ). Сократилось упоминание Великой Отечественной войны, «хрущевской оттепели» и довоенного периода с момента образования СССР. Вместе с тем увеличилось упоминание периода правления Брежнева и послевоенного периода (1945-1953 гг.).

Во-вторых, доля респондентов, считающих наиболее успешным период с 2000 г. по настоящее время, немного сократилась - с 23,4 до 22,5\%. При этом доля отметивших 2000-е гг. как успешные без упоминания личностей сократилась более существенно - с 21,2 до 16,6\%. Вместе с тем упоминание В.В. Путина в связи с обозначением успешного периода (путинский период, путинское правление, Путин и т.д.) несколько выросло - с 2,2 до 5,9\%.

В-третьих, довольно значительно выросла доля упоминающих более далекое прошлое как успешное. Так, дореволюционный период отметили в совокупности 31,0\% (в 2015 г. - 19,6\%). Из этого 18,2\% приходится на правление Петра I (в 2015 г. - 10,2\%) и 12,8\% (в 2015 г. - 9,4\%) на все остальные упоминания дореволюционной истории России (Российская империя, царская Россия, отдельные правители и т.д.).

В-четвертых, девяностые годы ХХ в. успешными признали лишь 1,1\% (в 2015 г. - 3,8\%). Перестройку не отметил никто (в 2015 г. - 3,2\%). 


\section{Советский период в темпоральной структуре современной России}

Советский период остается важной вехой, влияющей на процесс конструирования прошлого и будущего России. В последние несколько лет происходили активная «национализация ностальгии по СССР, трансформация образа СССР в положительную сторону, активное его использование в процессе нациестроительства» [14. С. 138]. В этой связи важно проследить изменения в массовых представлениях людей относительно возможности восстановления в том или ином виде советской системы. В анкете предлагались две взаимосвязанные позиции - необходимость отказа от попыток восстановления в том или ином виде советской системы и, наоборот, необходимость восстановления позитивного опыта советского времени.

Доля полностью согласных и несогласных с утверждением о необходимости отказа от попыток восстановления в каком-либо виде советской системы, как и двумя годами ранее, не сильно различается. В целом по выборке $22,4 \%$ респондентов полностью согласны с данным тезисом (в 2015 г. $20,8 \%$ ) и $24,6 \%$ несогласны (в 2015 г. $-21,6 \%$ ). Таким образом, наблюдается некоторый рост числа и полностью согласных, и полностью несогласных. Вместе с тем доля частично согласных немного уменьшилась - с 56,8 до $53,0 \%$.

По сравнению с результатами, полученными в 2015 г., доля полностью согласных с предложенным утверждением несколько увеличилась в младших поколенческих группах и довольно существенно сократилась в старших (табл. 3). Доля несогласных также выросла в младших группах и уменьшилась в старших. Несмотря на корректировку процентных показателей, младшие возрастные группы по данному вопросу опять показали более консервативную позицию. Фактически получается, что чем больше опыт жизни респондентов в советское время, тем более негативная реакция у них на возможность восстановления советской системы.

Таблица 3. Степень согласия с утверждением: «Современная Россия должна отказаться от попыток восстановления в том или ином виде советской системы», \%

\begin{tabular}{|l|c|c|c|c|c|c|c|c|}
\hline \multirow{2}{*}{ Вариант ответа } & \multicolumn{2}{|c|}{$\begin{array}{c}\text { Постсоветское } \\
\text { поколение }\end{array}$} & \multicolumn{2}{c|}{$\begin{array}{c}\text { Постсоветская пере- } \\
\text { ходная генерация }\end{array}$} & $\begin{array}{c}\text { Позднесоветское } \\
\text { поколение }\end{array}$ & \multicolumn{2}{c|}{$\begin{array}{c}\text { Советское } \\
\text { поколение }\end{array}$} \\
\cline { 2 - 10 } & 2015 & 2017 & 2015 & 2017 & 2015 & 2017 & 2015 & 2017 \\
\hline Полностью согласны & 22,1 & 23,3 & 21,2 & 26,0 & 25,8 & 15,2 & 34,8 & 27,7 \\
\hline Согласны частично & 53,3 & 47,9 & 60,3 & 46,0 & 50,8 & 63,6 & 43,2 & 53,2 \\
\hline Несогласны & 24,6 & 28,8 & 18,5 & 28,0 & 23,4 & 21,2 & 22,0 & 19,1 \\
\hline Всего & 100,0 & 100,0 & 100,0 & 100,0 & 100,0 & 100,0 & 100,0 & 100,0 \\
\hline
\end{tabular}

Позитивно оценили возможность восстановления в России всего хорошего, что было в СССР, 18,6\% (в 2015 г. - 22,1\%), не поддержали данное утверждение $40,7 \%$ (в 2015 г. - 29,4\%) и столько же респондентов отметили двойственную позицию, частично согласившись (в 2015 г. - 48,5\%). Таким образом, в целом по выборке доля несогласных с необходимостью восстановления положительных свойств советской системы возросла на порядок, а согласных с этим уменьшилась. 
Таблица 4. Степень согласия с утверждением: «Россия должна восстановить все хорошее, что было в СССР»

\begin{tabular}{|l|c|c|c|c|c|c|c|c|}
\hline \multirow{2}{*}{ Вариант ответа } & \multicolumn{2}{|c|}{$\begin{array}{c}\text { Постсоветское } \\
\text { поколение }\end{array}$} & \multicolumn{2}{c|}{$\begin{array}{c}\text { Постсоветская пере- } \\
\text { ходная генерация }\end{array}$} & $\begin{array}{c}\text { Позднесоветское } \\
\text { поколение }\end{array}$ & \multicolumn{2}{c|}{$\begin{array}{c}\text { Советское } \\
\text { поколение }\end{array}$} \\
\cline { 2 - 10 } & 2015 & 2017 & 2015 & 2017 & 2015 & 2017 & 2015 & 2017 \\
\hline Полностью согласны & 24,3 & 24,7 & 20,9 & 28,0 & 24,0 & 16,7 & 13,4 & 2,1 \\
\hline Согласны частично & 50,8 & 43,8 & 45,7 & 50,0 & 42,5 & 39,4 & 30,9 & 27,7 \\
\hline Не согласны & 24,9 & 31,5 & 33,4 & 22,0 & 33,5 & 43,9 & 55,7 & 70,2 \\
\hline Всего & 100,0 & 100,0 & 100,0 & 100,0 & 100,0 & 100,0 & 100,0 & 100,0 \\
\hline
\end{tabular}

Выделенные поколенческие группы по-разному оценивают необходимость восстановления позитивного опыта советского периода (табл. 4). Доля несогласных с этим на порядок выше в старших группах. Так, если в 2015 г. не поддерживали данный тезис 55,7\% представителей советского поколения, то в 2017 г. таковых уже 70,2\%. В группе позднесоветского поколения также уровень поддержки тезиса упал, а отрицательную позицию высказали на $10,4 \%$ больше респондентов. Данная тенденция в части повышения уровня отрицательной оценки возможности усвоения советского прошлого касается и постсоветского поколения. Постсоветская переходная генерация в этом вопросе довольно сильно отличается от других исследованных групп и демонстрирует усиление консервативной тенденции в выстраивании темпоральных представлений. В целом же, как и в 2015 г., в более молодых поколенческих группах наблюдается более консервативная позиция по данному вопросу.

\section{Представления об идеальной политической системе}

На протяжении всего постсоветского периода трансформации России не утихают споры относительно того, какая политическая система является лучшей, западная или советская, какую из них следовало бы взять за образец. Современная же система вплоть до начала двухтысячных чаще всего подвергалась вполне обоснованной критике. В нулевые годы современная российская политическая система многим даже стала нравиться. Эпоха дорогой нефти, сопровождаемая подъемом уровня жизни, стала ассоциироваться гражданами страны с качеством политической системы. В любом случае данная система стала способной противостоять, по крайней мере на уровне социальных предпочтений, как западной, так и советской модели.

Сравнивая результаты опросов 2017 и 2015 гг., можно отметить их достаточно несущественные различия. В целом по выборке количество считающих советскую систему лучшей уменьшилось незначительно - с 22,9\% в 2015 г. до 22,0\% в 2017 г. Современная российская политическая система представляется лучшей для $31,8 \%$ опрошенных, т.е. меньше на $3,6 \%$, чем в 2015 г. (35,4\%). Немного повысилась доля тех, кто считает лучшей политическую систему образца демократических западных стран - с 14,1\% в 2015 г. до 14,8\% в 2017 г. Вместе с тем выросла и доля затруднившихся с ответом: в 2015 г. - 27,9\%, в 2017 г. - 30,9\% (почти треть респондентов).

Поддержка советской политической системы немного уменьшилась в средних поколенческих группах (табл. 5), на порядок уменьшилась (почти на $10,0 \%$ ) у представителей самого старшего (советского) поколения и немного увеличилась (на 1,1\%) у постсоветского поколения. 
Таблица 5. Какая политическая система лучшая, \%

\begin{tabular}{|l|c|c|c|c|c|c|c|c|}
\hline \multirow{2}{*}{ Вариант ответа } & \multicolumn{2}{|c|}{$\begin{array}{c}\text { Постсоветское } \\
\text { поколение }\end{array}$} & \multicolumn{2}{c|}{$\begin{array}{c}\text { Постсоветская пере- } \\
\text { ходная генерация }\end{array}$} & $\begin{array}{c}\text { Позднесоветское } \\
\text { поколение }\end{array}$ & \multicolumn{2}{c|}{$\begin{array}{c}\text { Советское } \\
\text { поколение }\end{array}$} \\
\cline { 2 - 11 } & 2015 & 2017 & 2015 & 2017 & 2015 & 2017 & 2015 & 2017 \\
\hline Советская & 14,0 & 15,1 & 20,6 & 20,0 & 29,6 & 27,3 & 37,4 & 27,7 \\
\hline $\begin{array}{l}\text { Российская (в ее нынеш- } \\
\text { нем виде) }\end{array}$ & 35,5 & 26,0 & 37,3 & 26,0 & 37,3 & 37,9 & 29,8 & 38,3 \\
\hline $\begin{array}{l}\text { Демократия по образцу } \\
\text { западных стран }\end{array}$ & 17,8 & 26,0 & 16,4 & 20,0 & 7,7 & 7,6 & 9,4 & 4,3 \\
\hline Затруднились ответить & 32,7 & 32,9 & 25,7 & 34,0 & 25,4 & 27,3 & 23,4 & 29,8 \\
\hline Всего & 100,0 & 100,0 & 100,0 & 100,0 & 100,0 & 100,0 & 100,0 & 100,0 \\
\hline
\end{tabular}

Современная политическая система России в двух старших поколенческих группах оценивается более положительно, нежели в младших. Спустя два года представители младшего поколения оценили ее существенно ниже прежнего, тогда как представители самого старшего поколения, напротив, существенно выше. У позднесоветского поколения данный показатель поменялся несущественно.

Доля высоко оценивающих политическую систему западного образца среди двух более молодых поколений существенно выросла, в то же время среди самого старшего поколения существенно снизилась. У позднесоветского поколения данный показатель остался практически на прежнем уровне.

Таким образом, можно констатировать сохранение ключевых тенденций, выявленных в 2015 г. Во-первых, продолжение линии на политизацию истории страны, реализацию модели исторической политики, соответствующей административно-мобилизационной логике вертикально-интегрированного персоналистского политического режима. При этом очевидны признаки потери ее мобилизующей силы, нарастания на уровне общественного сознания скепсиса относительно данной линии по причине расхождения ее с реальностью, осознание ее как набора имитационных практик.

Во-вторых, в темпоральной конструкции образа России сохраняется приоритет прошлого. Однако в 2017 г. зафиксировано повышение степени идентификации респондентов с настоящим России и ее будущим. Это позволяет говорить о тенденции исчерпания энергетики прошлого в мобилизационно-консолидирующей политике, что, вероятно, выльется в ближайшее время в ее изменение в сторону повышения внимания к будущему, конструированию соответствующего нарратива «сверху».

B-третьих, сохранение консервативного тренда в конструировании национального нарратива об идеальном прошлом страны как на уровне политического дискурса, так и на уровне массовых представлений граждан. При этом консервативные настроения более выражены у молодых поколенческих групп, что, в частности, проявляется в оценке роли советского исторического опыта в конструировании будущего России. Однако ресурс «изобретающего воспоминания» $[15,16]$ о советском времени как о наиболее успешном периоде в истории России, по всей видимости, идет на убыль.

\section{Литература}

1. Крокинская O.K. Культурная память и опыт в практиках конструирования будущего обыденным сознанием // Журнал социологии и социальной антропологии. 2016. Т. 19, № 4 (87). C. $142-158$. 
2. Лотман Ю.М. Память культуры // Лотман Ю.М. Семиосфера. СПб.: Искусство-СПб, 2001. C. $614-621$.

3. Ачкасов B.A. Роль «исторической политики» в формировании российской идентичности // Журнал социологии и социальной антропологии. 2015. Т. 18, № 2 (79). С. 181-192.

4. Малинова О.Ю. Политическое использование прошлого как инструмент символической политики: эволюция дискурса властвующей элиты в постсоветской России // Политическая экспертиза: ПОЛИТЭКС. 2012. Т. 8, № 4. С. 179-204.

5. Головашина О.В. Образ Советского Союза в социальной памяти современных россиян (на материалах эмпирического исследования) // Социально-экономические явления и процессы. 2013. № 11. С. 193-198.

6. Гудков Л.Д. Время и история в сознании россиян (Ч. 1) // Вестник общественного мнения. Данные. Анализ. Дискуссии. 2009. № 3. С. 84-102.

7. Дубин Б.В. Символы возврата вместо символов перемен // Pro et contra. 2011. Т. 15, № 5. C. $6-22$.

8. Евгеньева T.B., Селезнева А.В. Советское прошлое в ценностном и образносимволическом пространстве российской идентичности // Полис. Политические исследования. 2016. № 3. C. 25-39.

9. Касамара В.А., Сорокина А. А. Образ СССР и современной России в представлениях студенческой молодежи // Общественные науки и современность. 2014. № 1. С. 107-118.

10. Гаврилюк В.В., Маленков В.В. Векторы развития России в сознании жителей российской провинции // Известия высших учебных заведений. Социология. Экономика. Политика. 2016. № 3. С. 65-69.

11. Левада Ю.А. Заметки о «проблеме поколений» // Мониторинг общественного мнения: экономические и социальные перемены. 2002. № 2. С. 9-11.

12. Семенова В.В. Современные концептуальные и эмпирические подходы к понятию «поколение» // Россия реформирующаяся: Ежегодник-2003. М.: ИС РАН, 2003. С. 213-233.

13. Дмитриев М.В. Парадоксы «Святой Руси»: Святая Русь и «русское» в культуре Московского государства 16-17 вв. и фольклоре 18-19 вв. // Cahiers du Monde russe. Avril-septembre 2012. 53/2-3. P. 319-331.

14. Маленков В.В. Образ советского прошлого в темпоральной конструкции формирующейся российской нации // Среднерусский вестник общественных наук. 2016. Т. 11, № 5 . C. $136-144$.

15. Головашина О. В. «Изобретающее воспоминание»: образ СССР в коммуникативной памяти первого постсоветского поколения // Конструктивные и деструктивные формы мифологизации социальной памяти в прошлом и настоящем: сборник статей и тезисов докладов Международной научной конференции. Тамбов: Изд-во Р.В. Першина, 2015. С. 250-255.

16. Реннер А. Изобретающее воспоминание: Русский этнос в российской национальной памяти // Российская империя в зарубежной историографии: Работы последних лет: антология. М.: Новое издательство, 2005. С. 436-472.

Malenkov Vyacheslav $\boldsymbol{V}$. Tyumen State University (Tyumen, Russian Federation)

E-mail: vvmalenkov@gmail.com

DOI: $10.17223 / 1998863 \mathrm{X} / 41 / 15$

TEMPORAL REPRESENTATION OF RUSSIA IN THE DYNAMICS OF NOTION OF TYUMEN RESIDENTS

Key words: nation, the historical memory, the temporal image of the country.

The temporal representation of the country is studied in the article as an important element of the national civic identity. This representation is an awareness of the past, present and future of the country and identification with it. The temporal strategy of the nation is formed at the macro level of society and present oneself the prevailing structure of the past fixed in the minds of the citizens of the country. In this meaning can speak about the nations of the past, present and future. Russia in this logic is a nation of the past. In the mass consciousness of Russian society circulates mythological ideas about the past of Russia. The article attempts to investigate some of these images and representations. The empirical base of this article is the data obtained as a result of a questionnaire survey conducted in MarchApril 2015 and March-April 2017 among adult residents of Tyumen (aged 17 and over). The dimension of the representative selection in both measurements was 1600 respondents. In the process of data analysis, four age groups were identified based on a generational approach: the Soviet generation (born before 1972), the late Soviet generation (1973-1984), the post-Soviet transition generation (born in 
1985-1993), the post-Soviet generation (1994-2000 years of birth). It can be stated the key tendency saved which identified in 2015. Firstly, the continuation of the line for the nationalization past of the country in the administrative-mobilization logic of a vertically integrated personalistic political regime. At the same time, there are obvious signs of a loss of its mobilizing power, a rise in the level of public consciousness of skepticism about this line because of its divergence from reality. Secondly, in the temporal construction of the representation of Russia, the priority of the past remains. However, in 2017, an increase in the degree of identification of respondents with the present of Russia and its future was recorded. This allows us to talk about the exhaustion of the energy of the past in the mobilization and consolidation policy, which is likely to result in its immediate change in the direction of increasing attention to the future, constructing the corresponding narrative "from above". Thirdly, the preservation of the conservative trend in the construction of a national narrative about the country's ideal past, both at the level of political discourse and at the level of mass representations of citizens. At the same time, conservative sentiments are more pronounced in young generation groups, which, in particular, is manifested in the assessment of the role of Soviet historical experience.

\section{References}

1. Krokinskaya, O.K. (2016) Cultural Memory and Experience in the Practice of Designing the Future in Everyday Consciousness. Zhurnal sotsiologii i sotsial'noy antropologii - Journal of Sociology and Social Anthropology. 4(87). pp. 142-158. (In Russian).

2. Lotman, Yu.M. (2001) Semiosfera [Semiosphere]. St. Petersburg: Iskusstvo-SPb. pp. 614621.

3. Achkasov, V.A. (2015) The Role of the "Politics of History" in the Formation of Russian Identity. Zhurnal sotsiologii i sotsial'noy antropologii - Journal of Sociology and Social Anthropology. 2(79). pp. 181-192. (In Russian).

4. Malinova, O.Yu. (2012) Politicheskoe ispol'zovanie proshlogo kak instrument simvolicheskoy politiki: evolyutsiya diskursa vlastvuyushchey elity v postsovetskoy Rossii [Political use of the past as an instrument of symbolic politics: The evolution of the ruling elite discourse in post-Soviet Russia]. Politicheskaya ekspertiza: POLITEKS - Political Expertise: POLITEX. 8(4). pp. 179-204.

5. Golovashina, O.V. (2013) Obraz Sovetskogo Soyuza v sotsial'noy pamyati sovremennykh rossiyan (na materialakh empiricheskogo issledovaniya) [The image of the Soviet Union in the social memory of modern Russians (empirical research)]. Sotsial'no-ekonomicheskie yavleniya i protsessy Social and Economic Phenomena and Processes. 11. pp. 193-198.

6. Gudkov, L.D. (2009) Vremya i istoriya v soznanii rossiyan (Chast' 1) [Time and history in the minds of Russians (Part 1)]. Vestnik obshchestvennogo mneniya. Dannye. Analiz. Diskussii. 3. pp. 84102.

7. Dubin, B.V. (2011) Simvoly vozvrata vmesto simvolov peremen [Symbols of return instead of symbols of change]. Pro et Contra. 15(5). pp. 6-22.

8. Yevgenyeva, T.V. \& Selezneva, A.V. (2016) Soviet Past in Value, Image and Symbolic Space of Russian Identity. Polis. Politicheskie issledovaniya - Polis. Political Studies. 3. pp. 25-39. (In Russian). DOI: $10.17976 / \mathrm{jpps} / 2016.03 .04$

9. Kasamara, V.A. \& Sorokina, A. A. (2014) Obraz SSSR i sovremennoy Rossii v predstavleniyakh studencheskoy molodezhi [The image of the USSR and modern Russia in the representations of student youth]. Obshchestvennye nauki i sovremennost' - Social Sciences and Contemporary World. 1. pp. $107-118$.

10. Gavrilyuk, V.V. \& Malenkov, V.V. (2016) Vektory razvitiya Rossii v soznanii zhiteley rossiyskoy provintsii [Vectors of Russia's development in the consciousness of the Russian province residents]. Izvestiya vysshikh uchebnykh zavedeniy. Sotsiologiya. Ekonomika. Politika. 3. pp. 65-69.

11. Levada, Yu.A. (2002) Zametki o "probleme pokoleniy" [Notes on the "generation problem"]. Monitoring obshchestvennogo mneniya: ekonomicheskie i sotsial'nye peremeny-Monitoring of Public Opinion: Economic and Social Changes Journal. 2. pp. 9-11.

12. Semenova, V.V. (2003) Sovremennye kontseptual'nye i empiricheskie podkhody k ponyatiyu "pokolenie" [Contemporary conceptual and empirical approaches to the notion of "generation"]. In: Drobizheva, L.M. (ed.) Rossiya reformiruyushchayasya: Ezhegodnik-2003 [Russia Under Reforms: Yearbook-2003]. Moscow: IS RAN, 2003. pp. 213-233.

13. Dmitriev, M.V. (2012) Paradoksy "Svyatoy Rusi": Svyataya Rus' i "russkoe" v kul'ture Moskovskogo gosudarstva 16-17 vv. i fol'klore 18-19 vv. [Paradoxes of "Holy Russia": Holy Russia and "Russian" in the culture of the Moscow state of the 16th-17th centuries and folklore of the 18th-19th centuries]. Cahiers du Monde russe. 53/2-3. pp. 319-331. 
14. Malenkov, V.V. (2016) An image of the Soviet past in the temporal structure of forming Russian nation. Srednerusskiy vestnik obshchestvennykh nauk - Central Russian Journal of Social Sciences. 11(5). pp. 136-144. (In Russian). DOI: 10.12737/22700

15. Golovashina, O.V. (2015) ["Inventive memory": the image of the USSR in the communicative memory of the first post-Soviet generation]. Konstruktivnye i destruktivnye formy mifologizatsii sotsial'noy pamyati v proshlom i nastoyashchem [Constructive and destructive forms of social memory mythologization in the past and present]. Proc. of the International Conference. Tambov, September 24-26, 2015. Tambov. pp. 250-255. (In Russian).

16. Renner, A. (2005) Izobretayushchee vospominanie: Russkiy etnos v rossiyskoy natsional'noy pamyati [Inventive recollection: Russian ethnos in the Russian national memory]. In: Leontieva, O. \& Dolbilov, M. (2005) Rossiyskaya imperiya v zarubezhnoy istoriografii. Raboty poslednikh let [Russian Empire in Foreign Historiography. Works of Recent Years]. TRanslated from English, German and French. Moscow: Novoe izdatel'stvo. pp. 436-472. 